\title{
QUALIDADE DE LEITES FERMENTADOS BRASILEIROS E ATIVIDADE ANTAGONISTA IN VITRO DE SUAS BACTÉRIAS ÁCIDO LÁTICAS
}

\author{
NATÁLIA PARMAAUGUSTO DE CASTILHO* \\ ADRIANO FRANÇA DA CUNHA** \\ MARIA MARLI PEREIRA E ARAÚJO***
}

\begin{abstract}
Avaliou-se a qualidade de cinco leites fermentados brasileiros, coletados em pontos de vendas de Viçosa (MG), assim como a atividade antagonista in vitro de suas bactérias ácido láticas para micro-organismos indicadores desejáveis e patogênicos. Todos os lotes avaliados estavam em conformidade com a legislação brasileira quanto ao teor de gordura e contagem de bolores e leveduras. Alguns lotes evidenciaram acidez titulável $(20 \%)$ e teor de proteína (52 \%) abaixo do limite permitido pela legislação nacional. Quanto à concentração de bactérias ácido láticas, 32 e $96 \%$ dos lotes não apresentaram contagens mínimas em conformidade com os limites estabelecidos pelo MAPA e pela ANVISA, respectivamente, o que implica na necessidade de fiscalização do produto. As bactérias ácido láticas demonstraram maior antagonismo para Salmonella enterica, Escherichia coli e Staphylococcus aureus que para a bactéria ácido lática utilizada como indicadora. Alguns lotes de leites fermentados não estavam em conformidade com a legislação, ainda que as bactérias ácido láticas avaliadas tenham importância para a preservação de produtos e controle de patógenos.
\end{abstract}

PALAVRAS-CHAVE: LEITE FERMENTADO; BACTÉRIA ÁCIDO LÁTICA; ANTAGONISMO.

* Médica Veterinária, Mestranda em Ciência e Tecnologia de Alimentos, Universidade Federal de Viçosa (UFV), Viçosa, MG (e-mail: nataliaparma@hotmail.com).

** Médico Veterinário, Doutorando em Ciência Animal, Universidade Federal de Minas Gerais (UFMG), Belo Horizonte (MG), Professor, Faculade de Ciências Biológicas e da Saúde, União do Ensino Superior de Viçosa (FACISA/UNIVIÇOSA), Viçosa, MG (e-mail: adrianofcunha@ufmg.br; adrianofcunha@hotmail. com.br).

*** Bióloga, Mestre em Ciência Animal, UFMG, Professora, Faculdade do Alto São Francisco (FASF) Luz, MG (e-mail: mmpafasf@gmail.com). 


\section{INTRODUÇÃo}

Leites fermentados são produtos resultantes da fermentação do leite por micro-organismos láticos, que devem ser viáveis, ativos e abundantes no produto final durante seu prazo de validade (BRASIL, 2007). A importância dos leites fermentados pode ser comprovada pela quantidade de marcas do produto em gôndolas de pequenos e grandes mercados. A expansão do produto se deve, entre outros fatores, ao valor nutritivo e sua associação à vida saudável (MAZIERO, TOLENTINO e WASZCZYNSKYJ, 2011).

A fermentação constitui método de preservação muito usado desde os primórdios da civilização pela falta de métodos de refrigeração, ou pasteurização de alimentos. Bactérias desejáveis utilizam a lactose para produção de energia, formando compostos carbonílicos e principalmente ácido lático, o que diminui o pH final do produto. Tal processo apresenta grande importância tecnológica para a preservação de alimentos, bem como para o controle de micro-organismos deteriorantes e patogênicos. Algumas dessas bactérias ácido láticas são espécies de Lactobacillus, Lactococcus, Leuconostoc, Streptococcus, Leuconostoc, Carnobacterium e Lactosphaera (HOLZAPFEL et al., 2001).

Algumas bactérias ácido láticas são designadas como probióticas, pois quando ingeridas viáveis e em quantidades adequadas exercem efeitos benéficos à saúde do hospedeiro (FAO/ WHO/OIE, 2003). Alguns desses efeitos incluem alívio dos sintomas da intolerância à lactose, modulação do sistema imune e da microbiota intestinal (tratamento e prevenção de diarreia), efeito hipocolesterolêmico e ação anticarcinogênica (FARIA, BENEDET e GUERROUE, 2006).

A atividade antagonista de bactérias ácido láticas, isoladas de queijos, para microorganismos patogênicos tem sido descrita em pesquisas científicas (CASLA, REQUENA e GOMEZ, 1996; SENA, 2000; ALEXANDRE, 2002; GUEDES NETO et al., 2005, ABO-AMER, 2007; COSTA, 2010). Essa atividade se deve à fermentação da lactose do leite em ácido lático e outras substâncias, denominadas bacteriocinas, as quais determinam diferentes atividades bactericidas e bacteriostáticas (ALM, 1991, NICOLI, 1995). No entanto, relatos sobre a atividade antagonista de bactérias ácido láticas isoladas de leites fermentados, assim como a avaliação das características físico químicas e microbiológicas do produto são escassos na literatura científica.

Os efeitos benéficos dos leites fermentados ao organismo ocorrem quando há concentrações de bactérias probióticas no lúmen do intestino do hospedeiro acima de $1 \times 10^{7} \mathrm{UFC} / \mathrm{g}$ de bolo fecal, o que muitas vezes depende da quantidade dessas bactérias no produto consumido (BOUHNIK, 1993; NICOLI, 1995). De acordo com a Agência Nacional de Vigilância Sanitária (BRASIL, 2008), o produto probiótico deve conter a quantidade mínima viável de cultura entre $1 \times 10^{8}$ e $1 \times 10^{9} \mathrm{UFC} / \mathrm{g}$ de produto. Já a Instrução Normativa 46, do Ministério da Agricultura, Pecuária e Abastecimento (BRASIL, 2007), estabelece limite mínimo de bactérias láticas de $1 \times 10^{6} \mathrm{UFC} / \mathrm{g}$ de produto como requisito de identidade e qualidade dos leites fermentados.

Verificar a qualidade dos produtos fermentados, assim como suas características probióticas assume importância para garantir o controle tecnológico do produto e a segurança alimentar. Portanto, o objetivo deste trabalho foi avaliar a qualidade de alguns leites fermentados brasileiros e testar a atividade antagonista in vitro de suas bactérias ácido láticas para micro-organismos desejáveis e patogênicos.

\section{MATERIAL E MÉTODOS}

Cinco lotes de leites fermentados desnatados de cinco marcas brasileiras diferentes (A, B, C, D e E) foram obtidos em pontos de vendas da cidade de Viçosa (MG). As 25 amostras foram 
levadas, rapidamente, acondicionadas em caixas isotérmicas para o Laboratório de Microbiologia da Faculdade de Ciências Biológicas e da Saúde (FACISA-UNIVIÇOSA), em Viçosa (MG), para serem submetidas a análises microbiológicas e físico-químicas.

Para o isolamento e enumeração de bactérias ácido láticas, todas as amostras de leite fermentado desnatado foram submetidas a diluições $\left(10^{-5}, 10^{-6}\right.$ e $\left.10^{-7}\right)$ em solução salina $0,85 \%$ peptonada $0,1 \%$. Posteriormente, uma alíquota de $100 \mu \mathrm{L}$ de cada diluição, em duplicata, foi vertida sobre placa de Petri contendo meio agar Mann, Roggosa e Sharpe (MRS - Difco, Detroit, United States). Os inóculos foram espalhados em superfície com o auxílio de alça de Drigalski e as placas incubadas de forma invertida em estufa, por 48 horas a $37^{\circ} \mathrm{C}$, sob aerobiose. A contagem de bactérias ácido láticas foi realizada em placas que apresentavam entre 40 e 250 colônias e os resultados expressos em UFC/mL. Após o isolamento, realizou-se a coloração de Gram para diferenciação morfotintorial das bactérias (APHA, 1992). A pesquisa de bolores e leveduras ocorreu de acordo com o MAPA (BRASIL, 2003), utilizando-se meio Potato Dextrose Agar (PDA - Difco, Detroit, United States).

Bactérias com características de ácido láticas pela diferenciação morfotintorial foram utilizadas na pesquisa da atividade antagonista. O teste de antagonismo in vitro foi realizado em duplicata de acordo com a técnica descrita por Tagg, Dajani e Wannamaker (1976). Duas ativações das bactérias ácido láticas, obtidas do isolamento (amostras produtoras), foram realizadas em caldo MRS (Difco) incubado a $37{ }^{\circ} \mathrm{C}$, por 48 horas, sob aerobiose. Em seguida, $10 \mu \mathrm{L}$ dos cultivos foram inoculados no centro de placas de Petri (spot) contendo agar MRS (Difco) e incubados a $37^{\circ} \mathrm{C}$, sob aerobiose, por 48 horas. Adicionou-se clorofórmio nas tampas das placas, deixando-o agir por 40 minutos a fim de eliminar os micro-organismos cultivados e a manutenção das possíveis substâncias inibidoras.

A atividade antagonista foi testada frente as bactérias indicadoras Salmonella enterica, Escherichia coli e Staphylococcus aureus, previamente identificadas e adquiridas do banco de bactérias da Universidade Federal de Viçosa (UFV). Bactéria produtora de leite fermentado também foi utilizada como indicadora (bactéria do produto C), após caracterização morfotintorial. Todas as bactérias indicadoras foram ativadas duas vezes a $37^{\circ} \mathrm{C}$, por 24 horas, sob aerobiose.

Transferiram-se $10 \mu \mathrm{L}$ dos cultivos de bactérias indicadoras, respectivamente, para $5 \mathrm{~mL}$ de ágares semi sólidos Brain Heart Infusion (3,7 \% de meio / 1,5\% de agar) (BHI - Oxoid, Basingstoke, England) e MRS (Difco) (5,5\% de meio / 0,75 \% de agar), mantidos em tubos de ensaio. Depois de agitação, os tubos foram vertidos sobre as placas de agar MRS (Difco) contendo as amostras de bactérias ácido láticas (spot), submetidas à ação do clorofórmio. As placas foram incubadas a $37^{\circ} \mathrm{C}$, durante 24 horas, sob aerobiose. Para a medida dos halos de inibição usou-se paquímetro digital (Mitutoyo Digimatic Caliper, Mitutoyo Sul Americana Ltda).

Logo após a avaliação microbiológica, os leites fermentados foram analisados quanto à acidez titulável, teores de proteína e gordura de acordo com a técnica descrita pelo MAPA (BRASIL, 2006).

A análise dos resultados de acidez titulável, teor de gordura e de enumeração de bactérias ácido láticas dos leites fermentados foi realizada de forma descritiva (BRASIL, 2006). Para os resultados da pesquisa de antagonismo in vitro, o teste não paramétrico de Kruskal-Wallis foi utilizado para comparação entre as médias dos halos de inibição, ao nível de $5 \%$ de significância (SAMPAIO, 2002).

\section{RESULTADOS E DISCUSSÃO}

Todas as amostras de leite fermentado estavam invioladas e sem alterações macroscópicas à coleta e início das análises (BRASIL, 2007). Ao teste de Gram, todas as marcas continham bactérias Gram positivas e em formato de bastonetes, características morfotintoriais compatíveis com Lactobacillus spp., gênero indicado nos rótulos dos produtos. Todas as marcas analisadas estavam em conformidade com a legislação quanto à designação, temperatura de estocagem (menor que 
$10^{\circ} \mathrm{C}$ ), teor de gordura (menor que 0,35\%) e contagem de bolores e leveduras (ausência) (BRASIL, 2007).

Todos os lotes de leites fermentados das marcas A, B, C e D (80 \%) apresentaram valores de acidez conforme os parâmetros estabelecidos pela legislação brasileira (Tabela 1), de 0,6 a $2,0 \mathrm{~g}$ de ácido láctico para cada $100 \mathrm{~g}$ do produto (BRASIL, 2007). No entanto, todos os lotes da marca $\mathrm{E}(20 \%)$ revelaram acidez titulável menor que $0,6 \mathrm{~g}$ de ácido lático/100 g, mostrando-se em desacordo com a legislação nacional. Resultados diferentes foram encontrados por Maziero, Tolentino e Waszczynskyj (2011) ao analisarem três marcas de leites fermentados comercializados em Curitiba (PR). Tais autores observaram que todas as marcas encontravam-se de acordo com a legislação nacional (BRASIL, 2007) quanto à acidez titulável.

\section{TABELA 1 - ACIDEZ TITULÁVEL (g DE ÁCIDO LÁTICO/100 g) EM CINCO MARCAS DE LEITE FERMENTADO COMERCIALIZADAS EM VIÇOSA (MG)}

\begin{tabular}{ccccccc}
\hline \multirow{2}{*}{ Marcas } & \multicolumn{5}{c}{ Lotes } & \multirow{2}{*}{ Média } \\
\cline { 2 - 6 } & 1 & 2 & 3 & 4 & 5 & 1,02 \\
\hline A & 1,04 & 1,10 & 0,96 & 1,04 & 0,97 & 1,12 \\
B & 1,10 & 1,15 & 1,01 & 1,06 & 1,27 & 1,65 \\
C & 1,71 & 1,66 & 1,47 & 1,54 & 1,89 & 1,35 \\
D & 1,35 & 1,38 & 1,37 & 1,29 & 1,37 & 0,57 \\
E & 0,56 & 0,56 & 0,59 & 0,59 & 0,54 & \\
\hline
\end{tabular}

Os lotes do produto $C$ apresentaram maior acidez média ( $1,65 \mathrm{~g}$ de ácido lático/100 g) e os do produto $\mathrm{E}$ a menor acidez média $(0,57 \mathrm{~g}$ de ácido lático/100 g). Em condições de crescimento bacteriano não adequadas, a acidez do leite não aumenta comprometendo a neutralização das cargas das proteínas e, consequentemente, a coagulação do produto. $\mathrm{O}$ efeito da acidez sobre a coagulação durante a produção de leites fermentados é direto (atuando juntamente com a temperatura e concentração de oxigênio na promoção da coagulação), já que as bactérias ácido láticas são anaeróbias. Além disso, a acidez da matéria-prima utilizada influencia a acidez do produto final em razão da dificuldade de proliferação das bactérias láticas no início da fermentação (KRISTO, BILIADERIS e TZANETAKIS, 2003).

A acidez do leite fermentado pode aumentar mesmo durante a estocagem do produto. Isso depende do tempo de seu armazenamento, da temperatura de refrigeração e do poder pósacidificação das culturas usadas (THAMER e PENNA, 2006). Zacarchenco e Massaguer-Roig (2004) observaram que durante todo o período de estocagem, o leite fermentado por Streptococcus thermophillus apresentou maior acidez do que leites fermentados por Bifidobacterium longum e Lactobacillus spp. Assim, a variação da acidez encontrada no presente trabalho também pode ter sido influenciada pela utilização de diferentes tipos de bactérias ácido láticas. A acidez do leite fermentado pode limitar a aceitação do produto pelo consumidor, pois esse atributo exerce grande influência sobre a qualidade dos produtos lácteos fermentados.

Das 25 amostras de leite fermentado analisadas, 13 (52 \%) apresentaram teor de proteína abaixo do parâmetro estabelecido pela legislação nacional (BRASIL, 2007), como pode ser observado na Tabela 2. Rodas et al. (2001) encontraram $50 \%$ das amostras de oito marcas diferentes de leite fermentado com valores de proteína abaixo do recomendado pela legislação. Já Alves (2007), em estudo realizado com 11 amostras de leite fermentado, verificou que 10 amostras $(87,5 \%)$ apresentaram teor de proteína inferior ao exigido pela legislação brasileira.

Os lotes das marcas A e E apresentaram maior teor médio de proteína (2,44 e 2,37 \%) que os demais. A composição nutricional do produto depende diretamente da qualidade da matériaprima e dos ingredientes adicionados. A adição de soro e leite desnatado pode influenciar os teores de proteína em produtos lácteos fermentados (THAMER e PENNA, 2006). 
TABELA 2 - TEOR DE PROTEÍNA EM CINCO MARCAS DE LEITE FERMENTADO COMERCIALIZADAS EM VIÇOSA (MG)

\begin{tabular}{ccccccc}
\hline \multirow{2}{*}{ Marcas } & \multicolumn{5}{c}{ Lotes } & \multirow{2}{*}{ Média } \\
\cline { 2 - 5 } & 1 & 2 & 3 & 4 & 5 & \\
\hline A & 2,62 & 2,44 & 2,62 & 2,62 & 1,92 & 2,44 \\
B & 1,74 & 1,39 & 1,57 & 1,74 & 1,74 & 1,63 \\
C & 1,57 & 1,39 & 1,74 & 2,27 & 1,74 & 1,74 \\
D & 1,92 & 2,27 & 1,92 & 1,92 & 2,27 & 2,06 \\
E & 2,96 & 2,09 & 2,27 & 2,09 & 2,44 & 2,37 \\
\hline
\end{tabular}

Três lotes da marca $B$, dois da marca $D$ e três da marca $E$ (32 \% dos lotes), não apresentaram contagens de bactérias ácido láticas maiores que $1 \times 10^{6} \mathrm{UFC} / \mathrm{mL}$ (Tabela 3), estando em desconformidade com os padrões do MAPA (BRASIL, 2007). Quanto ao parâmetro estabelecido pela ANVISA, 24 lotes (96 \%) não apresentaram contagem acima de $1 \times 10^{8} \mathrm{UFC} / \mathrm{mL}$ (BRASIL, 2008). A concentração de bactérias ácido láticas encontrada provavelmente permitiria aporte de $1 \times 10^{7} \mathrm{UFC} / \mathrm{mL}$ de bactérias no intestino delgado de hospedeiros em razão da sensibilidade dessas bactérias aos sucos gástrico e biliar (BOUHNIK, 1993; NICOLI, 1995).

\section{TABELA 3 - ENUMERAÇÃO DE BACTÉRIAS ÁCIDO LÁTICAS (UFC/mL) EM CINCO MARCAS DE LEITE FERMENTADO COMERCIALIZADAS EM VIÇOSA (MG)}

\begin{tabular}{ccccccc}
\hline \multirow{2}{*}{ Marcas } & \multicolumn{5}{c}{ Lotes } & \multirow{2}{*}{ Média } \\
\cline { 2 - 5 } & 1 & 2 & 3 & 4 & 5 & \\
\hline A & $2,7 \times 10^{7}$ & $3,6 \times 10^{7}$ & $3,5 \times 10^{7}$ & $2,1 \times 10^{7}$ & $2,5 \times 10^{6}$ & $2,4 \times 10^{7}$ \\
B & $<10^{6}$ & $<10^{6}$ & $2,7 \times 10^{6}$ & $<10^{6}$ & $1,7 \times 10^{7}$ & $<4,5 \times 10^{6}$ \\
C & $8,3 \times 10^{6}$ & $1,0 \times 10^{7}$ & $1,1 \times 10^{7}$ & $8,4 \times 10^{6}$ & $1,9 \times 10^{7}$ & $1,1 \times 10^{7}$ \\
D & $<10^{6}$ & $2,6 \times 10^{6}$ & $1,8 \times 10^{6}$ & $<10^{6}$ & $5,9 \times 10^{6}$ & $<2,5 \times 10^{6}$ \\
E & $<10^{6}$ & $<10^{6}$ & $<10^{6}$ & $1,3 \times 10^{6}$ & $9,3 \times 10^{8}$ & $<1,9 \times 10^{8}$ \\
\hline
\end{tabular}

Assis et al. (2009) avaliaram 29 lotes de leite fermentado e observaram contagens abaixo de $1 \times 10^{6} \mathrm{UFC} / \mathrm{mL}$ (BRASIL, 2007) em quatro deles (13,8 \%). No entanto, 13 lotes (44,8 \%) não apresentaram contagens acima de $1 \times 10^{8} \mathrm{UFC} / \mathrm{mL}$ (BRASIL, 2008). Avaliando cinco amostras de bebidas lácteas fermentadas coletadas em indústrias, Tebaldi et al. (2007) observaram que apenas uma apresentava contagem de bactérias ácido láticas em conformidade com o MAPA (contagem mínima de $1 \times 10^{6} \mathrm{UFC} / \mathrm{mL}$ ) para tal produto (BRASIL, 2007).

A alta temperatura favorece o crescimento dos micro-organismos, os quais produzem ácidos, elevando a acidez titulável do produto (HOLZAPFEL et al., 2001). No entanto, dada a baixa acidez titulável encontrada (Tabela 1), a temperatura de estocagem provavelmente não interferiu na quantidade de bactérias ácido láticas. A variação na contagem de bactérias ácido láticas entre os lotes pode ser explicada por falhas no monitoramento de pontos críticos de controle durante a fabricação do produto (ARAÚJO, 2009). As condições da temperatura de processamento, concentração de oxigênio do leite, quantidade e poder de acidificação da cultura utilizada são as causas das baixas contagens de bactérias viáveis (SVENSSON, 1999).

Gomes e Malcata (1999) relataram os seguintes pré-requisitos para se obter altas contagens de células viáveis em produtos fermentados: controle da assepsia de equipamentos e adição de promotores de crescimento bacteriano no produto. Segundo SVENSSON (1999), a adição 
de hidrolisados proteicos de caseína ou soro, glicose, vitaminas, minerais e extrato de leveduras podem estimular a multiplicação e a sobrevivência das culturas bacterianas.

As baixas contagens de bactérias ácido láticas demonstram o risco dos produtos não promoverem adequadamente efeitos benéficos aos consumidores. A efetiva fiscalização na indústria e pontos de vendas torna-se necessária para prevenir a baixa quantidade de bactérias ácido láticas no produto final.

Quanto à atividade antagonista in vitro das bactérias ácido láticas isoladas dos leites fermentados analisados (Tabela 4), as bactérias produtoras apresentaram maior $(p<0,05)$ poder de inibição dos indicadores patogênicos que para a bactéria ácido lática utilizada como indicadora (bactéria do produto C). Entretanto, a bactéria produtora da marca $\mathrm{A}$ apresentou grande inibição da indicadora Escherichia coli.

\section{TABELA 4 - RESULTADOS MÉDIOS (MILÍMETROS) DO TESTE DE ANTAGONISMO IN VITRO DE BACTÉRIAS ÁCIDO LÁTICAS ISOLADAS DE LEITES FERMENTADOS COMERCIALIZADOS EM VIÇOSA (MG) FRENTE À MICRO-ORGANISMOS INDICADORES}

\begin{tabular}{lccccc}
\hline \multirow{2}{*}{ Micro-organismos Indicadores } & \multicolumn{5}{c}{ Marcas } \\
\cline { 2 - 6 } & $\mathrm{A}$ & $\mathrm{B}$ & $\mathrm{C}$ & $\mathrm{D}$ & $\mathrm{E}$ \\
\hline Bactéria ácido lática $(\mathrm{C})$ & $1,09^{\mathrm{Aa}}$ & $1,13^{\mathrm{Aa}}$ & $0,30^{\mathrm{Aa}}$ & $0,53^{\mathrm{Aa}}$ & $0,04^{\mathrm{Aa}}$ \\
Salmonella entérica & $26,61^{\mathrm{Bb}}$ & $14,12^{\mathrm{Bab}}$ & $13,31^{\mathrm{Ba}}$ & $14,79^{\mathrm{Bab}}$ & $15,19^{\mathrm{Bab}}$ \\
\hline Staphylococcus aureus & $19,88^{\mathrm{Ba}}$ & $12,38^{\mathrm{Ba}}$ & $16,34^{\mathrm{Ba}}$ & $15,81^{\mathrm{Ba}}$ & $14,17^{\mathrm{Ba}}$ \\
\hline Escherichia coli & $41,60^{\mathrm{Cb}}$ & $15,44^{\mathrm{Ba}}$ & $17,96^{\mathrm{Ba}}$ & $19,98^{\mathrm{Ba}}$ & $13,24^{\mathrm{Ba}}$ \\
\hline
\end{tabular}

Letras minúsculas distintas na mesma linha ou maiúsculas distintas na mesma coluna diferem estatisticamente pelo teste de Kruskal-Wallis $(\mathrm{p}<0,05)$. Espécies segundo o rótulo: $\mathrm{A}=$ Lactobacillus casei; $\mathrm{B}=$ Lactobacillus fortis; $\mathrm{C}=$ Lactobacillus casei; $\mathrm{D}=$ Lactobacillus protecttus; $\mathrm{E}=$ Lactobacillus casei .

Quando se comparou a atividade antagonista das bactérias produtoras entre as marcas avaliadas, observou-se que a média dos halos de inibição da bactéria ácido lática indicadora $C \mathrm{e}$ de Staphylococcus aureus foram estatisticamente iguais $(p>0,05)$. A bactéria produtora da marca $A$ apresentou maior inibição para Salmonella entérica que a da marca $E$, além de maior inibição de Escherichia coli que todas as bactérias produtoras das outras marcas.

A atividade antagonista de espécies de bactérias ácido láticas isoladas de queijos para espécies de gêneros como Salmonella, Staphylococcus, Escherichia, Shigella, Listeria, Pediococcus e Enterococcus foi descrita em outros relatos científicos (CASLA REQUENA e GOMEZ, 1996; SENA, 2000; ALEXANDRE, 2002; GUEDES NETO et al., 2005; ABO-AMER, 2007; COSTA, 2010). Apesar de não ter sido avaliada a natureza das substâncias antagonistas produzidas pelas culturas, as atividades inibitórias verificadas justificam-se pela evidência da produção de substâncias que se difundem pelo ágar e impedem o crescimento das culturas indicadoras. A mesma evidência foi constatada por GUEDES NETO et al. (2005).

Os resultados da atividade antagonista demonstram a importância tecnológica de bactérias ácido láticas para a preservação de alimentos, bem como para o controle de patógenos e efeitos benéficos à saúde humana. Esse fato assume maior importância se for considerado o desafio dos profissionais das indústrias para produzirem alimentos saudáveis e nutritivos em grande quantidade. Os resultados obtidos permitem indicar o uso das bactérias analisadas na fabricação desses produtos, juntamente com outras bactérias ácido láticas (já que não houve inibição da bactéria indicadora C), aumentando a ação inibitória para outros micro-organismos patogênicos.

\section{CONCLUSÃO}

Todas as amostras de leite fermentado apresentaram teor de gordura e contagem de bolores 
e leveduras em conformidade com a legislação brasileira em vigor. No entanto, algumas amostras não apresentaram acidez titulável e teor de proteína em conformidade com a referida legislação.

A maioria dos leites fermentados não continha a quantidade mínima viável de bactérias ácidas láticas estabelecidas pela legislação nacional, tornando necessária a fiscalização dos produtos na indústria e pontos de vendas a fim de garantir o aporte bacteriano desejável ao consumidor.

As bactérias ácido láticas dos leites fermentados apresentaram atividade antagonista satisfatória para micro-organismos desejáveis e patogênicos, podendo ser utilizadas em associação com outras bactérias ácido láticas para a bioconservação desses produtos e controle de patógenos.

\section{ABSTRACT \\ QUALITY OF BRAZILIAN FERMENTED MILKS AND ANTAGONISTIC ACTIVITY "IN VITRO" OF THEIR LACTIC ACID BACTERIA}

It was evaluated the quality of five Brazilian fermented milks collected from markets of Viçosa (MG, BRAZIL), as well as the antagonistic in vitro activity of their lactic acid bacteria against desirable and pathogenic microorganisms. It was observed that all the samples were in accordance with the Brazilian legislation (MAPA) regarding fat tenor, count of molds and yeasts. Some batches showed titratable acidity $(20 \%)$ and protein tenor (52\%) bellow the specified by the Law. As for the concentration of lactic acid bacteria, 32 and $96 \%$ of the batches didn't present values in accordance with the MAPA and ANVISA, respectively, indicating that inspection of these products is required. However, the lactic acid bacteria showed greater antagonism against Salmonella enterica, Escherichia coli and Staphylococcus aureus than against lactic acid bacteria, used as indicator. Some batches of fermented milk were not in accordance with the legislation, though their lactic acid bacteria are important in the preservation of products and pathogen control.

KEY-WORDS: FERMENTED MILK; LACTIC ACID BACTERIA; ANTAGONISM.

\section{REFERÊNCIAS}

1 ABO-AMER, A.E. Molecular characterization of antimicrobial compound produced by Lactobacillus acidophilus AA11. Acta Microbiologica Immunologica Hungarica, v.54, n.2, p.107-119, 2007.

2 ALEXANDRE, D.P.; SILVA, M.R.; SOUZA, M.R.; SANTOS, W.L.M. Atividade antimicrobiana de bactérias lácticas isoladas de queijo de minas artesanal do Serro (MG) frente a microorganismos indicadores. Arquivo Brasileiro de Medicina Veterinária e Zootecnia, v.54, n.4, p.424-428, 2002.

3 ALM, L. The therapeutic effects of various cultures: an overview. In: ROBINSON, R.K. (Ed.). Therapeutic properties of fermented milks. London: Elsevier, 1991. p. 45-64.

4 ALVES, L. Avaliação das características físico-químicas de leites fermentados inspecionados, comercializados no município do Rio de Janeiro. 2007. 56 f. Monografia (Especialização em Higiene e Inspeção de Produtos de Origem Animal) - Universidade Castelo Branco, Rio de Janeiro, 2007.

5 APHA. American Public Health Association. Compendium of methods for the microbiological examination of foods. $3^{\text {rd }}$ ed. Washington, 1992. $1219 \mathrm{p}$.

6 ARAÚJO, M.M.P.; CUNHA, A.F.; LAGE, A.D.; COUTO, C.N.B.; CERQUEIRA, M.M.O.P.; SOUZA, M.R. Enumeração de Lactobacillus spp. em leites fermentados probióticos comercializados em Belo Horizonte e Luz. In: ENCONTRO NACIONAL, e CONGRESSO LATINO AMERICANO DE ANALISTAS DE ALIMENTOS, 2., Belo Horizonte, 2009, Anais... Belo Horizonte: SBAAL, 2009.

7 ASSIS, B.S.; CUNHA, A.F.; COSTA, H.H.S.; PENNA. C.F.A.M.; LEITE, M.O.; CERQUEIRA, M.M.O.P.; FONSECA, L.M.; SOUZA, M.R. Enumeração de Lactobacillus spp. em leites fermentados probióticos comercializados em Belo Horizonte. Higiene Alimentar, v.23, p.95-96, 2009.

8 BOUHNIK, Y. Survie et effets chez l'homme des bactéries ingérées dans les laits fermentes. Lait, v.73, p.241-247, 1993.

9 BRASIL. Ministério da Agricultura, Pecuária e Abastecimento. Instrução Normativa $n^{\circ} 62$ de 26 de agosto de 2003. Métodos analíticos oficiais para análises microbiológicas para controle de produtos de origem animal e água. Diário Oficial [da] República Federativa do Brasil, Brasília, DF, seção 1, p.14, 18 set. 2003.

10 BRASIL. Ministério da Agricultura, Pecuária e Abastecimento. Instrução Normativa n 68 de 12 de dezembro de 2006. Métodos analíticos oficiais físico-químicos para controle de leite e produtos lácteos. Diário Oficial [da] República Federativa do Brasil, Brasília, DF, seção 1, p.8, 14 set. 2006. 
11 BRASIL. Ministério da Agricultura, Pecuária e Abastecimento. Instrução Normativa n 46 de 23 de outubro de 2007. Regulamento técnico de identidade e qualidade de leites fermentados. Diário Oficial [da] República Federativa do Brasil, Brasília, DF, seção 1, p.5, 24 out. 2007.

12 BRASIL. Ministério da Saúde. Agência Nacional de Vigilância Sanitária (ANVISA). Alimentos com alegação de propriedades funcionais e ou de saúde, novos alimentos/ingredientes, substâncias bioativas e probióticos, 2008. Disponível em: http://www.anvisa.gov.br/alimentos/comissoes/tecno_lista_alega.htm Acesso em: 25 de fevereiro 2012.

13 CASLA, D.; REQUENA, T.; GOMEZ, R. Antimicrobial activity of lactic acid bacteria isolated from goat's milk and artisanal cheeses: characteristics of a bacteriocin produced by Lactobacillus curvatus IFPLI 05. Journal of Applied Bacteriology, v.81, p.35-41, 1996.

14 COSTA, H.H.S. Potencial probiótico de Lactobacillus spp. e Weisella paramesenteroides isolados de queijo minas artesanal da serra da canastra - MG. 2010. 60 p. Dissertação (Mestrado em Ciência Animal) - Universidade Federal de Minas Gerais, Belo Horizonte, 2010

15 FARIA, C.P.; BENEDET, H.D.; GUERROUE, J.L.L. Análise de leite de búfula fermentado por Lactobacillus casei e suplementado com Bifidobacterium longum. Ciências Agrárias, v.27, n.3, p.407-414, 2006.

16 GOMES, A.M.P.; MALCATA, F.X. Agentes probióticos em alimentos: aspectos fisiológicos e terapêuticos, e aplicações tecnológicas. Boletim de Biotecnologia Alimentar, n.64, p.12-22, 1999.

17 GUEDES NETO, L.G.; SOUZA, M.R.; NUNES, A.C.; NICOLI, J.R.; SANTOS, W.L.M. Atividade antimicrobiana de bactérias ácido-lácticas isoladas de queijo de coalho artesanal e industrial frente a micro-organismos indicadores. Arquivo Brasileiro de Medicina Veterinária e Zootecnia, v.57, n.2, p.245-250, 2005.

18 HOLZAPFEL, H.W.; HABERER, P.; GEISEN, R.; BJÖRKROTH, J.; SCHILLINGER, U. Taxonomy and important features of probiotic microorganisms in food and nutrition. The American Journal of Clinical Nutrition, v.73, p.365S-373, 2001.

19 WHO/FAO/OIE. World Health Organization/Food and Agricultural Organization/World Organization for Animal Health. Background document for the Joint WHO/FAO/OIE expert. In: WORKSHOP ON NON-HUMAN ANTIMICROBIALS USAGE AND ANTIMICROBIALS RESISTANCE SCIENTIFIC ASSESSMENT, 2003, Geneva, Switzerland. Electronic Proceedings... Geneva: WHO/FAO/OIE, 2003. Disponível em: http://www.who.int/foodsafety/publications/micro/en/amr. pdf Acesso em: 23, out., 2012.

20 KRISTO, E.; BILIADERIS, C.G.; TZANETAKIS, N. Modelling of rheological, microbiological and acidification properties of a fermented milk product containing a probiotic strain of Lactobacillus paracasei. International Dairy Journal, v.13, p.517-528, 2003.

21 MAZIERO, M.T.; TOLENTINO, M.C.; WASZCZYNSKYJ, N. Propriedades sensoriais e físico-químicas de leites fermentados comerciais. Revista Brasileira de Tecnologia Agroindustrial, v.5, n.1, p.274-281, 2011.

22 NICOLI, J.R. Normal gastrointestinal microbiota in domestic animals and human beings. Enfermidades Infecciosas y Microbiologia, v.15, p.183-190, 1995.

23 RODAS, M.A.B.; RODRIGUES, R.M.M.S.; SAKUMA, H.; TAVAREZ, L.Z.; SGARBI, C.R.; LOPES, W.C.C. Caracterização físico-química, histológica e viabilidade de bactérias lácticas em iogurtes com frutas. Ciência e Tecnologia de Alimentos, v.21, p.304-309, 2001

24 SAMPAIO, I.B.M. Estatística aplicada à experimentação animal. Belo Horizonte: Fundação de Ensino e Pesquisa em Medicina Veterinária e Zootecnia, 2002. 265 p.

25 SENA, M.J. Perfil epidemiológico, resistência a antibióticos e aos conservantes nisina e sistema lactoperoxidase de Staphylococcus sp. isolados de queijos coalho comercializados em Recife - PE. 2000. 75 f. Tese (Doutorado em Ciência Animal) - Escola de Veterinária, Universidade Federal de Minas Gerais, Belo Horizonte, 2000.

26 SVENSSON, U. Industrial perspectives. In: TANNOCK, G.W. (Ed.) Probiotics: a critical review. Wymondham: Horizon Scientific Press, 1999. p.57-64.

27 TAGG, J.R.; DAJANI, A.S.; WANNAMAKER, L.W. Bacteriocins of gram-positive bacteria. Bacterial Reviews, v.40, p.722$756,1976$.

28 THAMER, K.G.; PENNA, A.L.B. Caracterização de bebidas lácteas funcionais fermentadas por probióticos e acrescidas de prebiótico. Ciência e Tecnologia de Alimentos, v.26, n.3, p.589-595, 2006.

29 TEBALDI, V.M.R.; RESENDE, J.G.O.S.; RAMALHO, G.C.A.; OLIVEIRA, T.L.C.; ABREU, L.R.; PICCOLI, R.H. Avaliação microbiológica de bebidas lácteas fermentadas adquiridas no comércio varejista do sul de Minas. Ciências Agrotécnicas, v.31, n.4, p.1085-1088, 2007.

30 ZACARCHENCO, P.B.; MASSAGUER-ROIG, S. Avaliação sensorial, microbiológica e de pós acidificação durante a vida-de-prateleira de leites fermentados contendo Streptococcus thermophilus, Bifidobacterium longum e Lactobacillus acidophilus. Ciência e Tecnologia de Alimentos, v.24, p.674-679, 2004. 